\title{
List of abbreviations and symbols
}

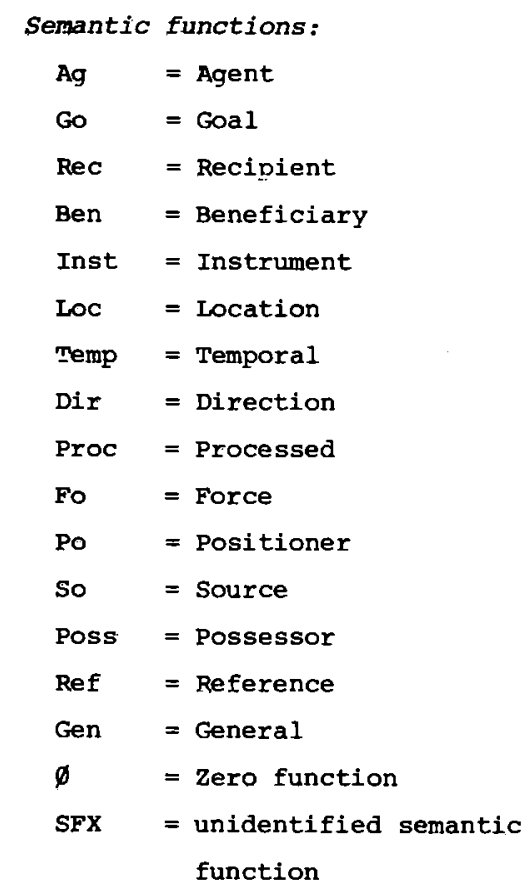

Emp = Emphatic

Categories:

$\begin{array}{ll}\text { A } & \text { = Adjectival } \\ \text { N } & =\text { Nominal } \\ \text { V } & =\text { Verbal } \\ \text { Vf } & =\text { finite Verb } \\ \text { Vi } & =\text { infinite Verb } \\ \text { PRO } & =\text { Pronoun } \\ \text { NP } & =\text { Noun Phrase } \\ \text { PNP } & =\text { Prepositional Phrase } \\ \text { NPP } & =\text { Postpositional Phrase }\end{array}$

Term operators:
d $=$ definite
$i$ = indefinite
1 , sg = singular
m, pl = plural

Morpho-syntactic categories:

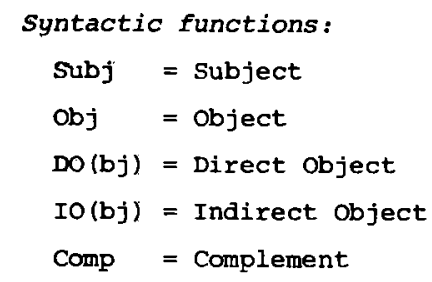

Pragmatic functions:

$\begin{aligned} \text { TOP } & =\text { Topic } \\ \text { Foc } & =\text { Focus } \\ \text { Ass } & =\text { Assertive }\end{aligned}$


Positions :

$\begin{array}{ll}\text { S } & \text { Subject position } \\ \text { O } & =\text { Object position } \\ \text { V } & =\text { Verb position } \\ \text { P1 } & =\text { Clause-initial position } \\ \text { P2 } & =\text { Theme position } \\ \text { P3 } & =\text { Tail position }\end{array}$

P3 $\quad$ Tail position

$\begin{aligned} \text { Cases: } & \\ \text { nom } & =\text { nominative } \\ \text { acc } & =\text { accusative } \\ \text { gen } & =\text { genitive } \\ \text { dat } & =\text { dative } \\ \text { abl } & =\text { ablative }\end{aligned}$

Constructions and markers:

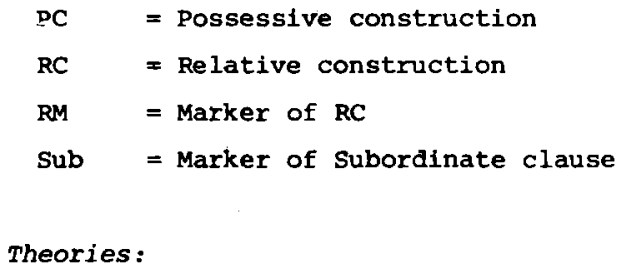

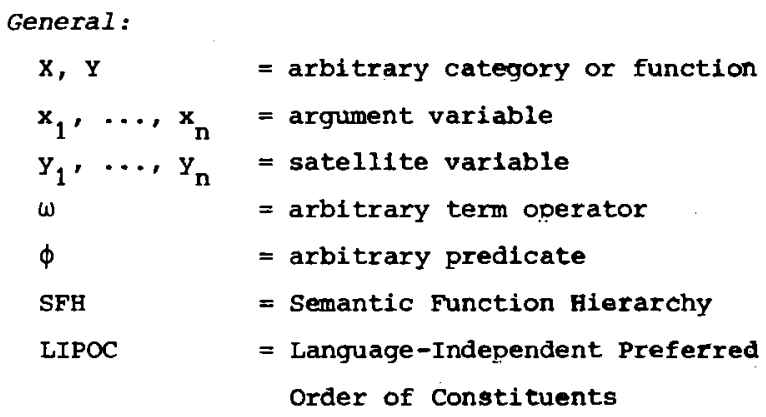

